Supplement of Geosci. Model Dev., 13, 4287-4303, 2020

https://doi.org/10.5194/gmd-13-4287-2020-supplement

(C) Author(s) 2020. This work is distributed under

the Creative Commons Attribution 4.0 License.

(c) (1)

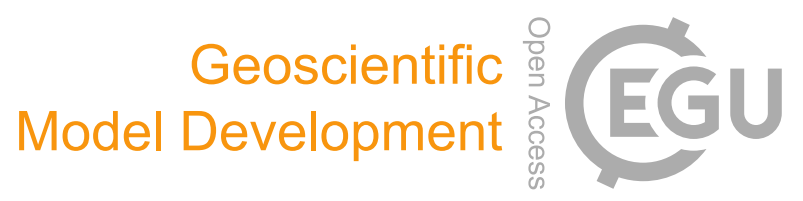

Supplement of

\title{
Modelling mineral dust emissions and atmospheric dispersion with MADE3 in EMAC v2.54
}

\section{Christof G. Beer et al.}

Correspondence to: Christof Beer (christof.beer@dlr.de)

The copyright of individual parts of the supplement might differ from the CC BY 4.0 License. 
This Supplement contains additional figures complementing the evaluation of our model results presented in Sect. 3 of the paper. Details about each figure can be found in the corresponding sections of the paper as mentioned in the supplement figure captions. 

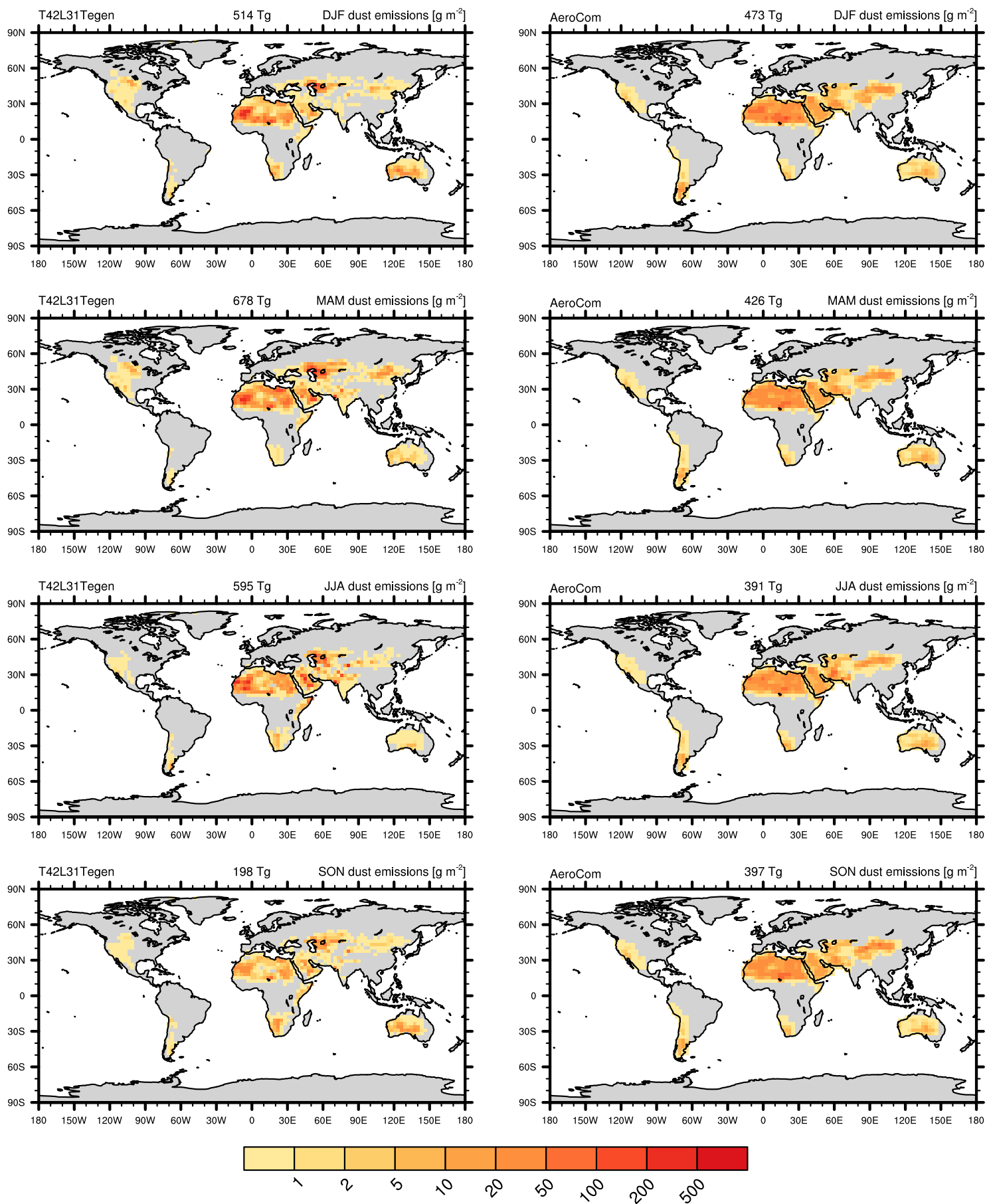

Figure S1. Similar to Fig. 2, but showing the global seasonal (from top to bottom: DJF, MAM, JJA, SON) dust emissions in the T42L31Tegen (left column) and T42L31AeroCom (right column) setup. Emissions are given in units of $\mathrm{gm}^{-2}$. Total seasonal dust emissions are shown at the top of each plot in units of $\mathrm{Tg}$. 


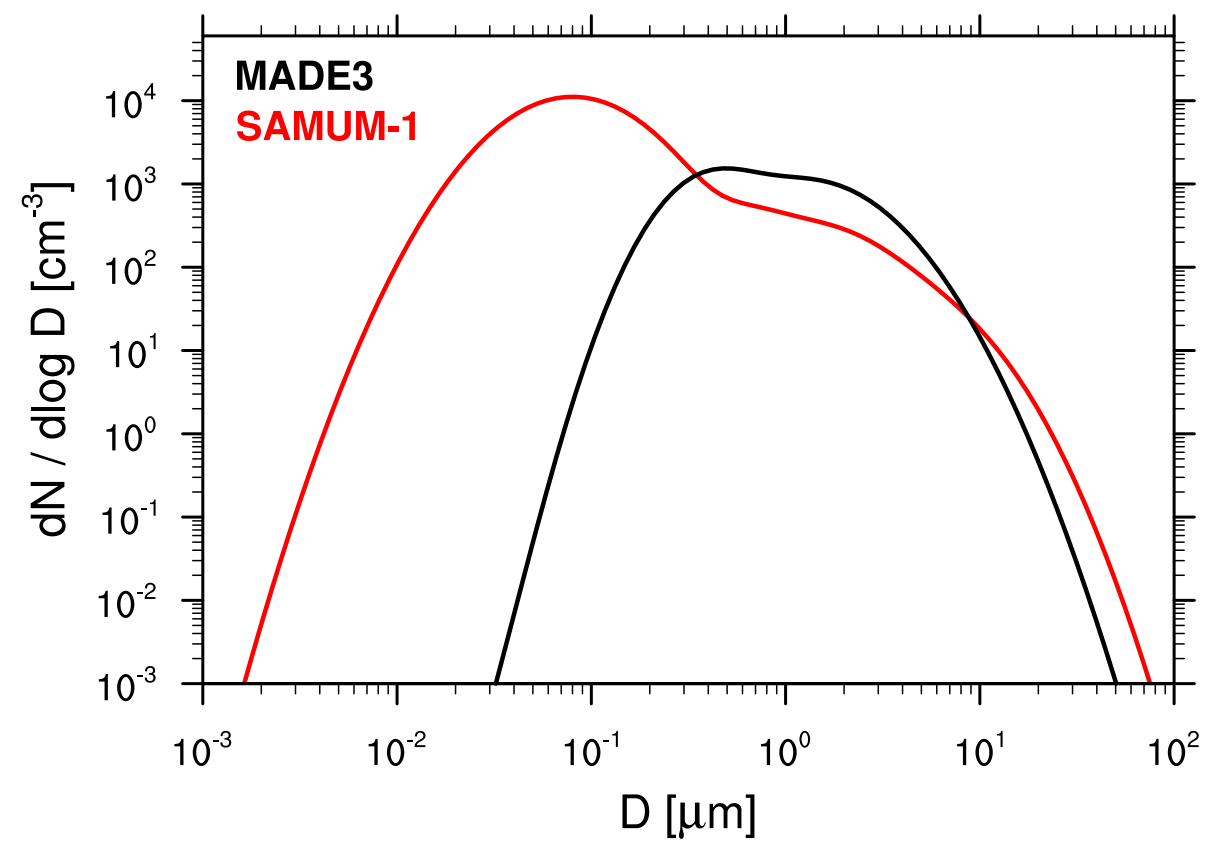

Figure S2. Number size distributions of emitted mineral dust assumed in MADE3, for the reference case (MADE3, black) and the sensitivity study (SAMUM-1, red). The size distributions were calculated for the year 2006 and the region of $0^{\circ}-40^{\circ} \mathrm{N}$ and $20^{\circ} \mathrm{W}-0^{\circ} \mathrm{E}$, which includes the Western Sahara where the SAMUM observations took place. For the SAMUM-1 distribution, median diameters and geometric standard deviations were taken from Weinzierl et al., 2011 (their Table 5). 

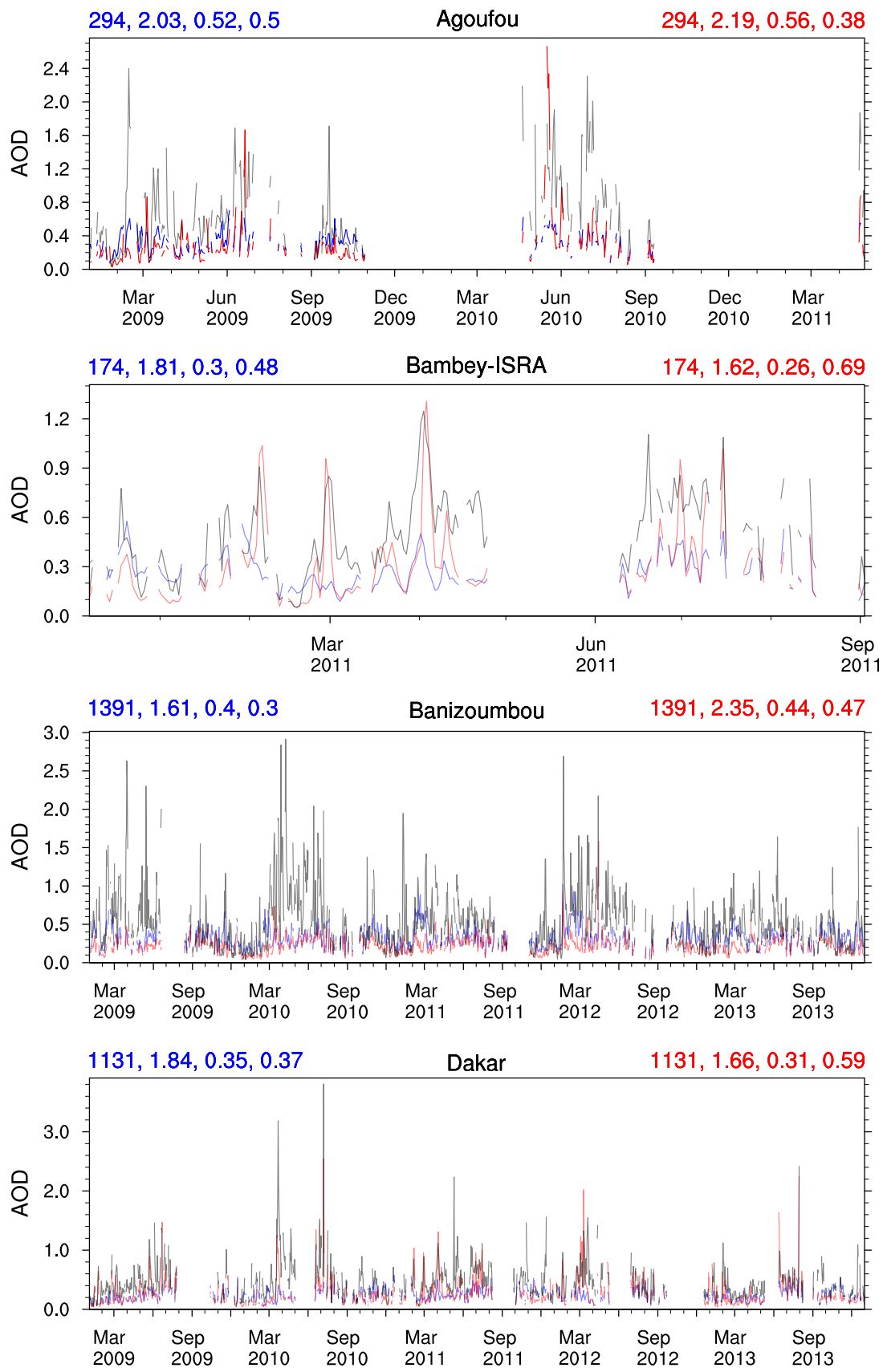

Figure S3. Similar to Fig. 3, but comparing model (T42L31 AeroCom in blue, T42L31Tegen in red) and AERONET (grey) AOD timeseries for all 17 stations depicted in Fig. 4a, showing the full comparison period (2009/01 - 2013/12). Gaps in the timeseries correspond to missing observations. The numbers at the top left and right represent the number of data points, the ratio of averages of observation and model data, root mean square error, and Pearson correlation coefficient, for the two model setups, respectively. 

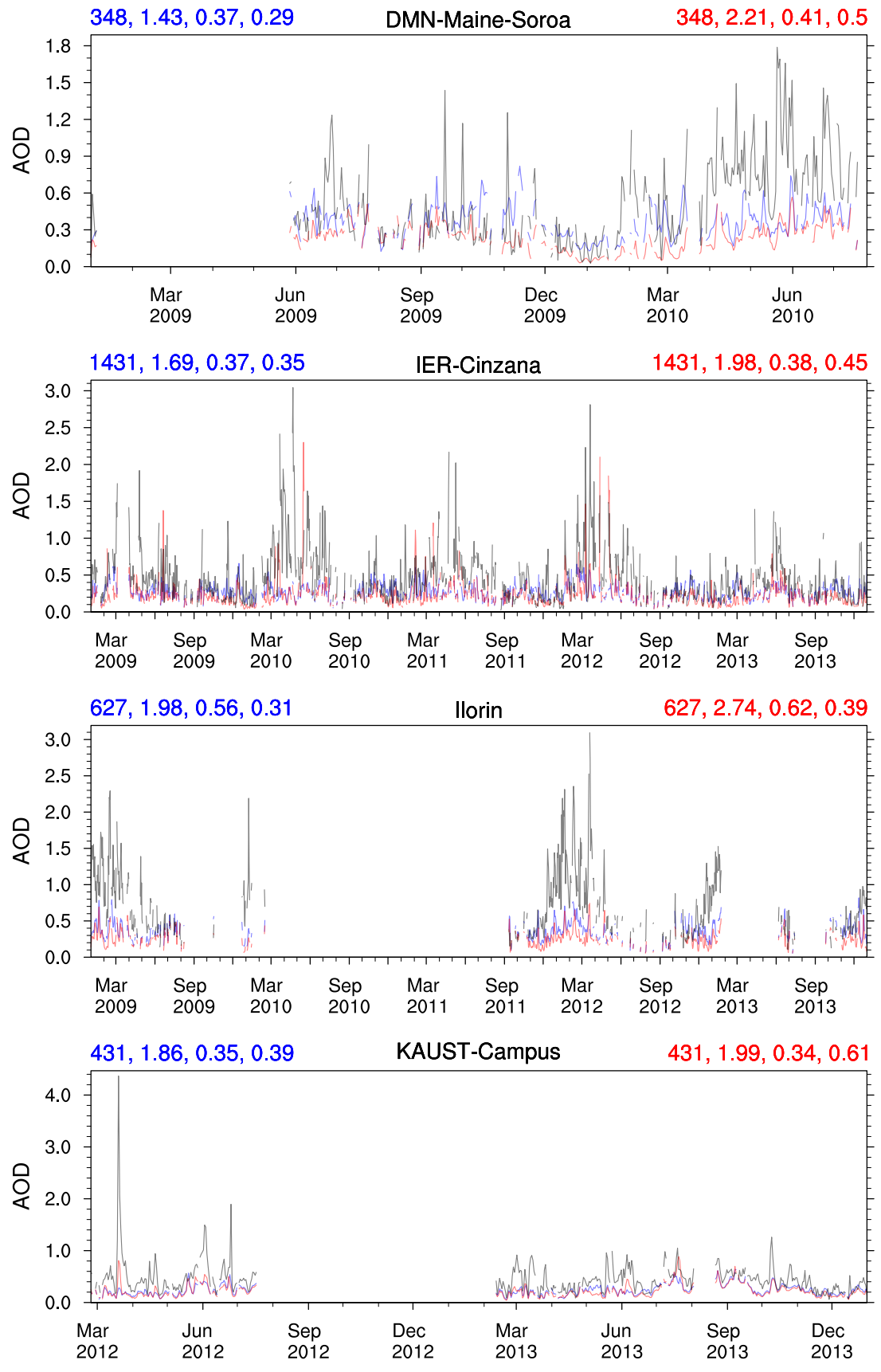

Figure S3. Continued. 

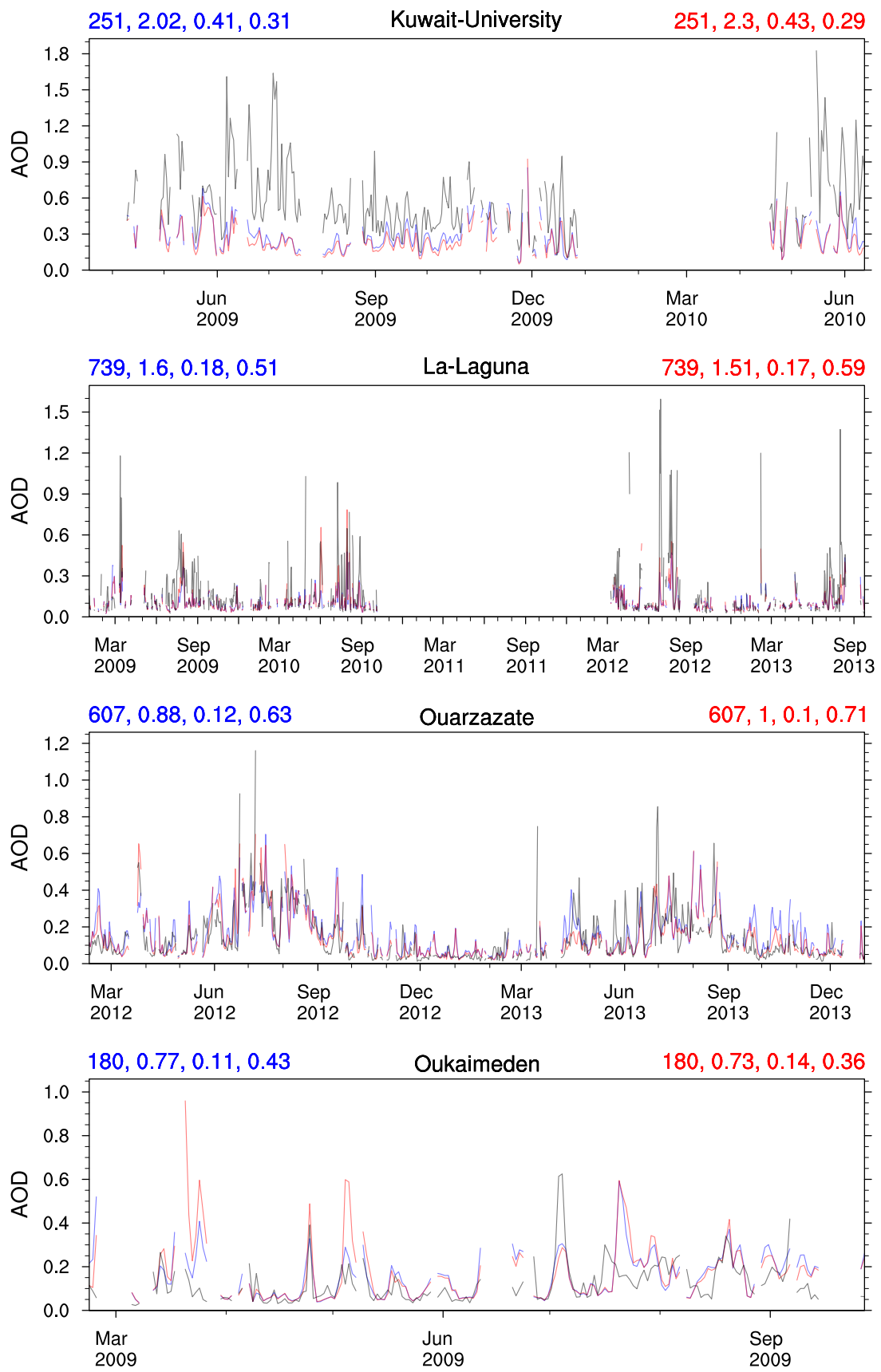

Figure S3. Continued. 

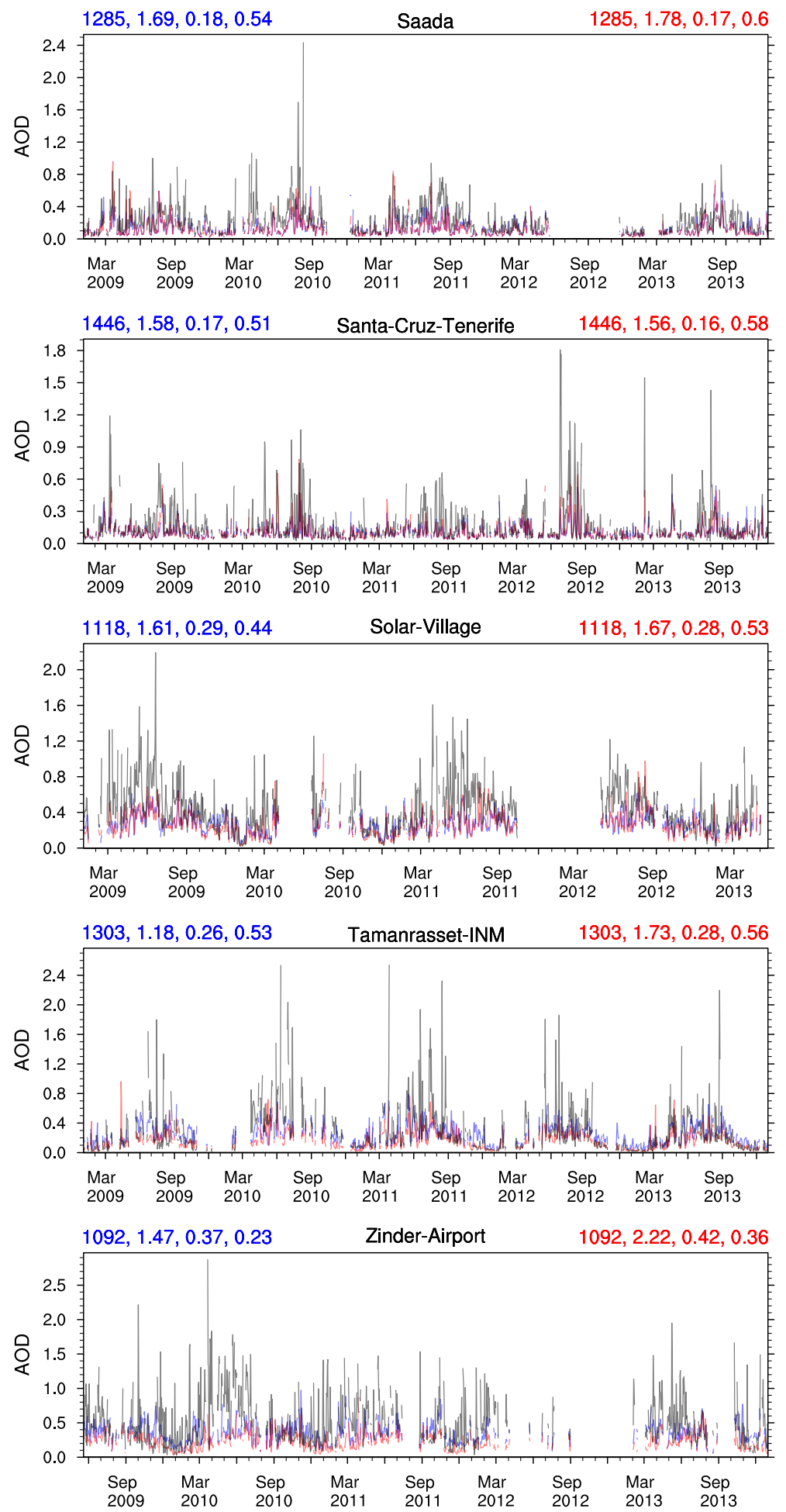

Figure S3. Continued. 

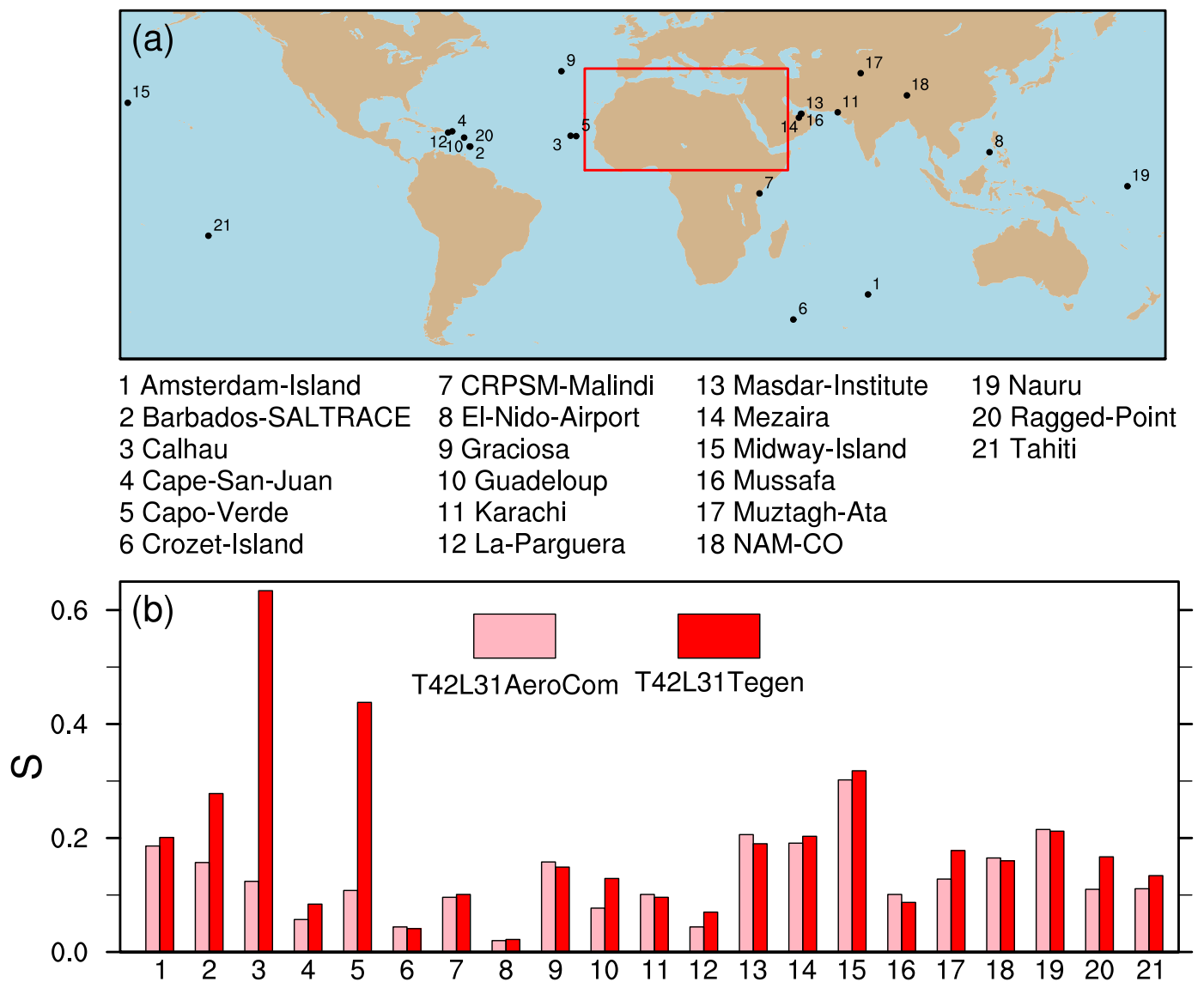

Figure S4. As in Fig. 4, but showing results for AERONET stations outside the region of $5^{\circ} \mathrm{N}-40^{\circ} \mathrm{N}$ and $20^{\circ} \mathrm{W}-50^{\circ} \mathrm{E}$, for the time period 2009 - 2013. Stations with Ångstrom exponents of AE $<0.75$ (AE averaged over the time period 2009 - 2013) and a minimum of 50 observation days were selected. 
(a) SALTRACE (aircraft) vs. EMAC (MADE3)

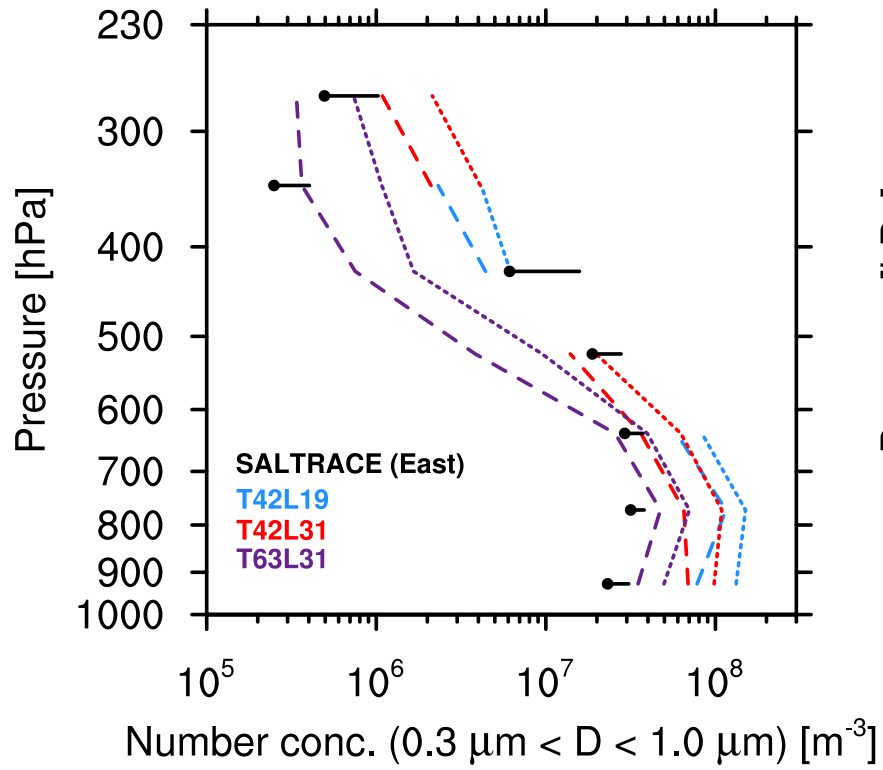

(b) SALTRACE (aircraft) vs. EMAC (MADE3)

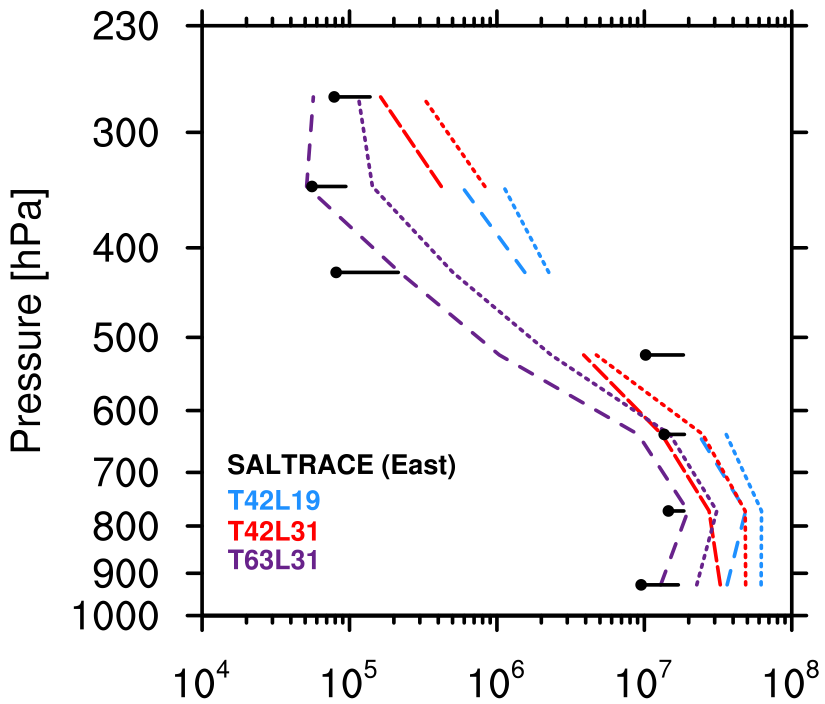

Number conc. $(0.7 \mu \mathrm{m}<\mathrm{D}<50 \mu \mathrm{m})\left[\mathrm{m}^{-3}\right]$

Figure S5. As in Fig. 5, but comparing model results with observational data from SALTRACE-East (region around Cabo Verde). A vertical binning of $1.5 \mathrm{~km}$ was employed. Missing values for the model curves result from too few data points available for a meaningful calculation of average and standard deviation in that bin. See Sect. 3.2 in the paper for details. 

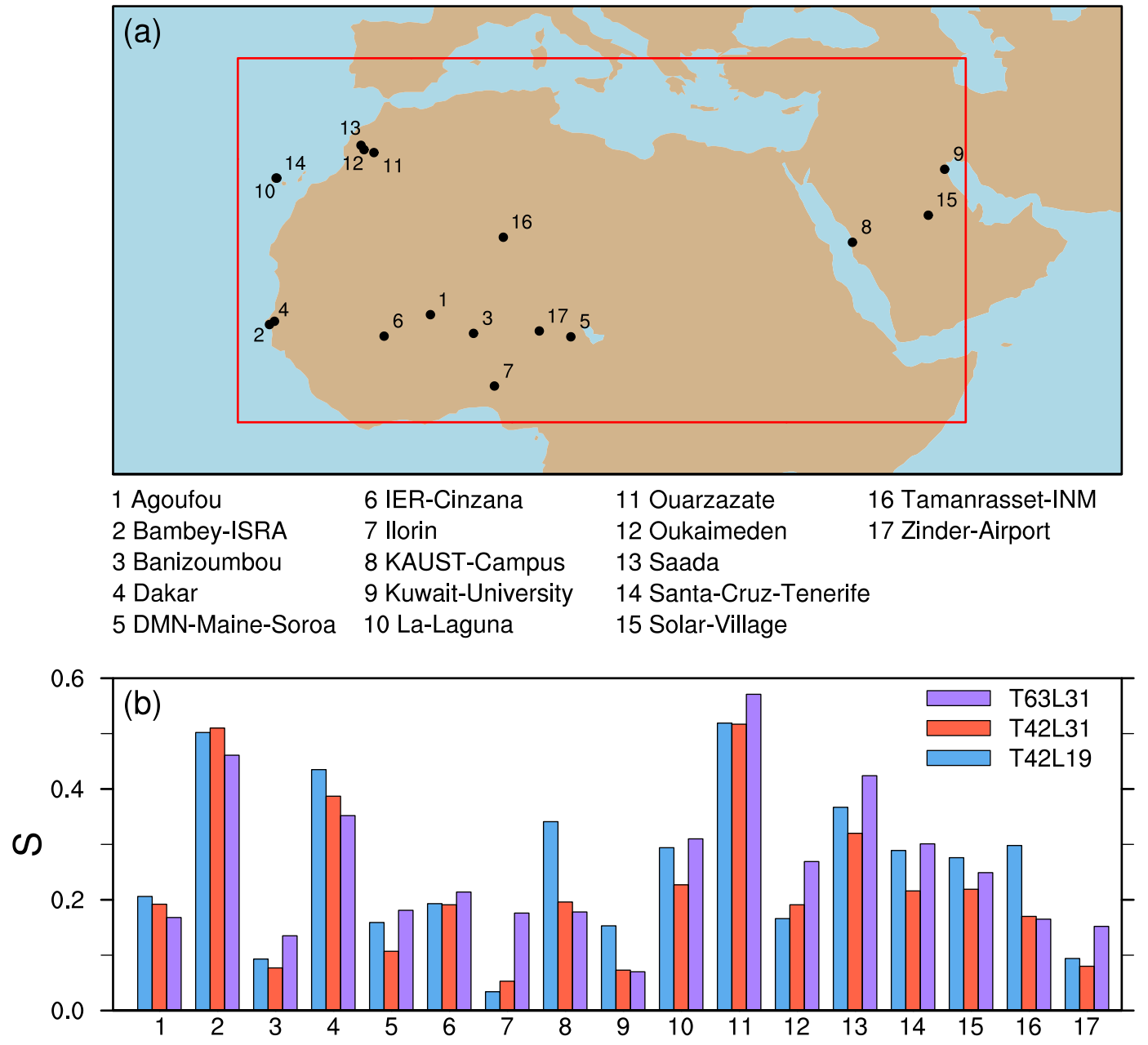

Figure S6. As in Fig. 4, but comparing model results for the three different model resolutions (T42L19 in blue, T42L31 in red, T63L31 in purple). 


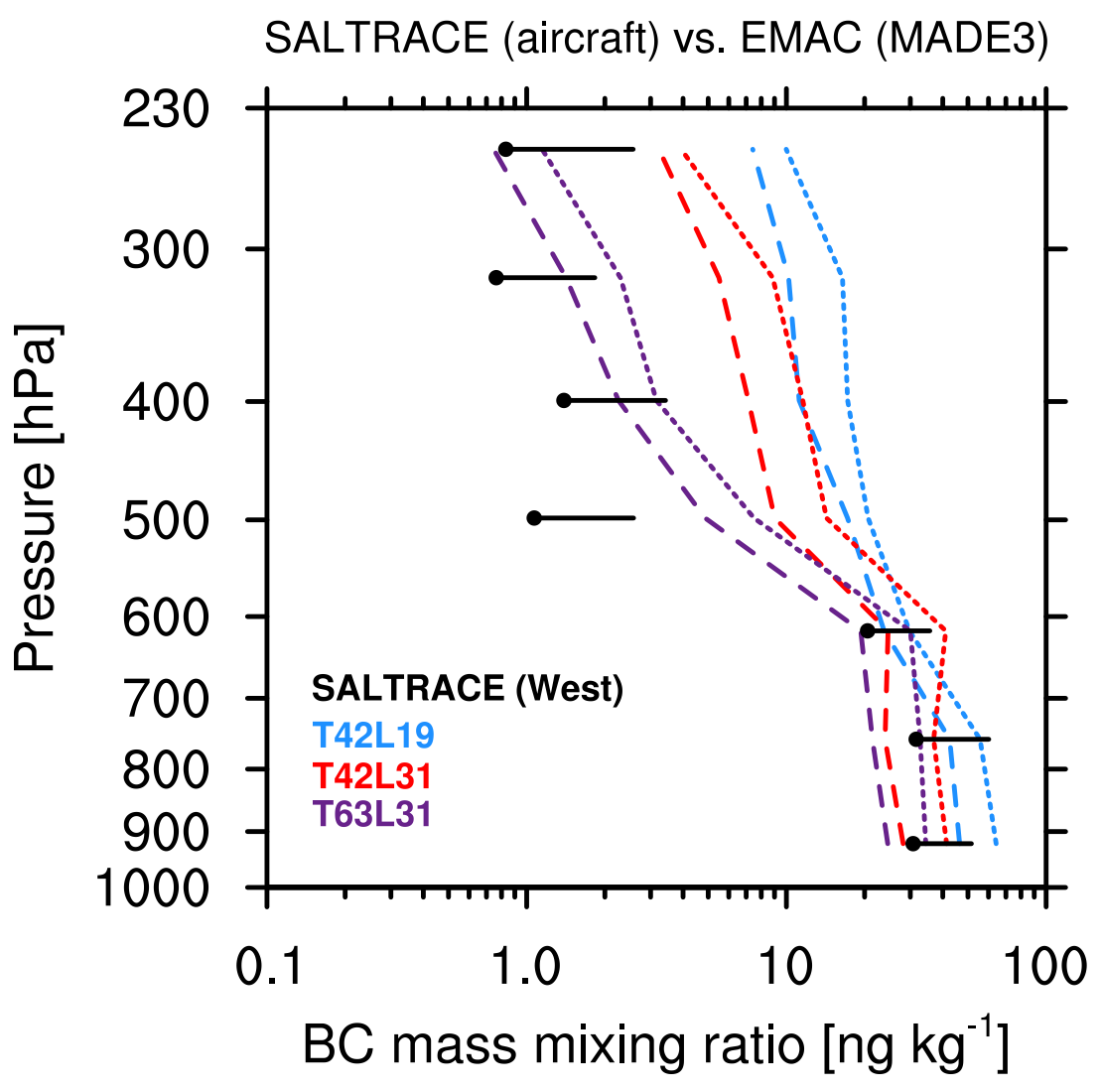

Figure S7. Similar to Fig. 5a,b , but comparing black carbon mass mixing ratio profiles for SALTRACE observations and model results. 

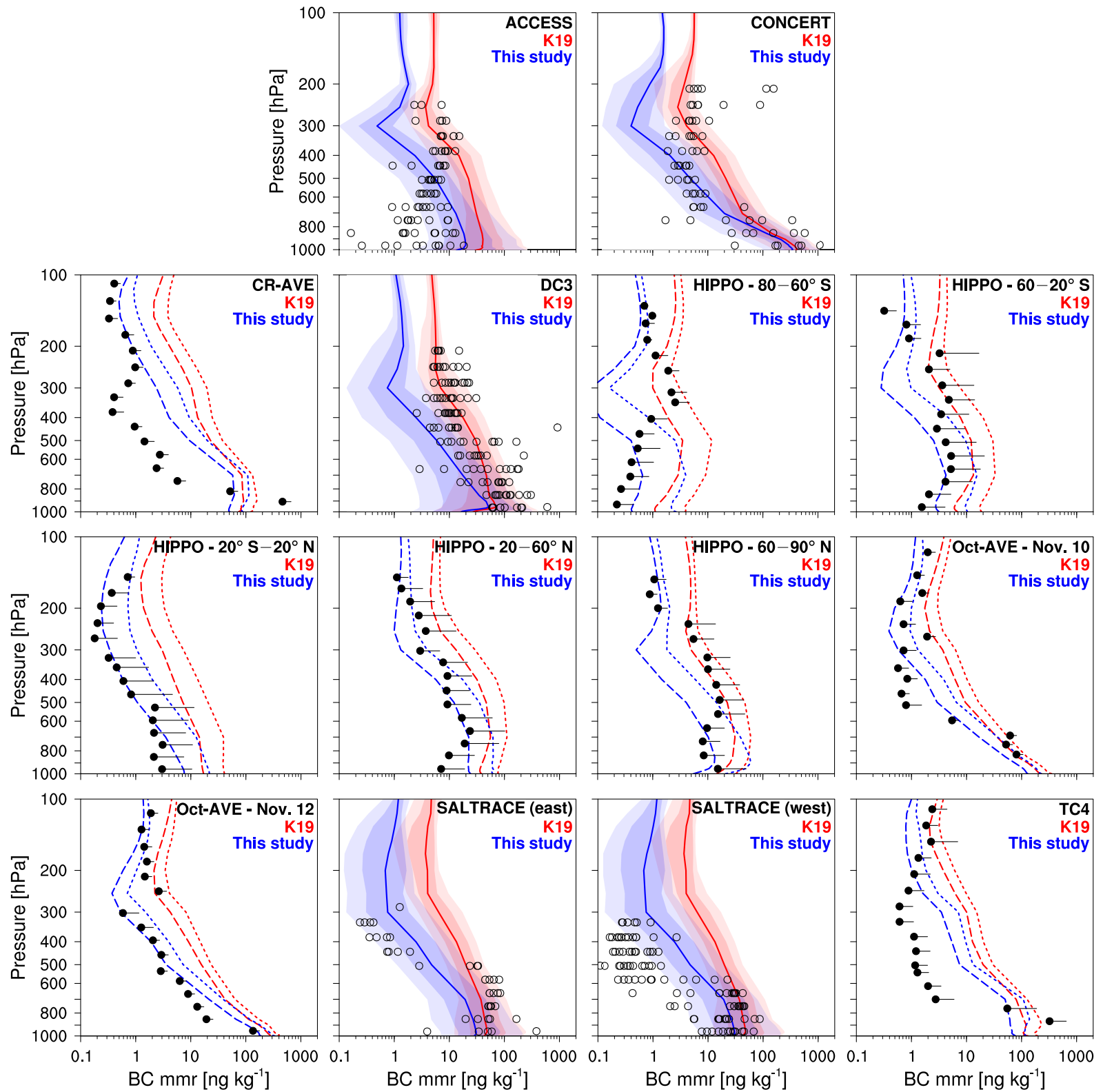

Figure S8. As in Kaiser et al. (2019), their Fig. 5, comparing various aircraft measurements of BC (black) with their results (K19, red) and with results from the T63L31Tegen setup presented in this work (blue). Dashed lines and filled circles represent mean values; dotted lines and whiskers represent standard deviations, which are only shown in the direction of larger values for clarity. Solid lines stand for median values. Light and dark shadings indicate the 10th to 90th, and 25th to 75th percentiles, respectively. Hollow circles are the median values of individual flights. 

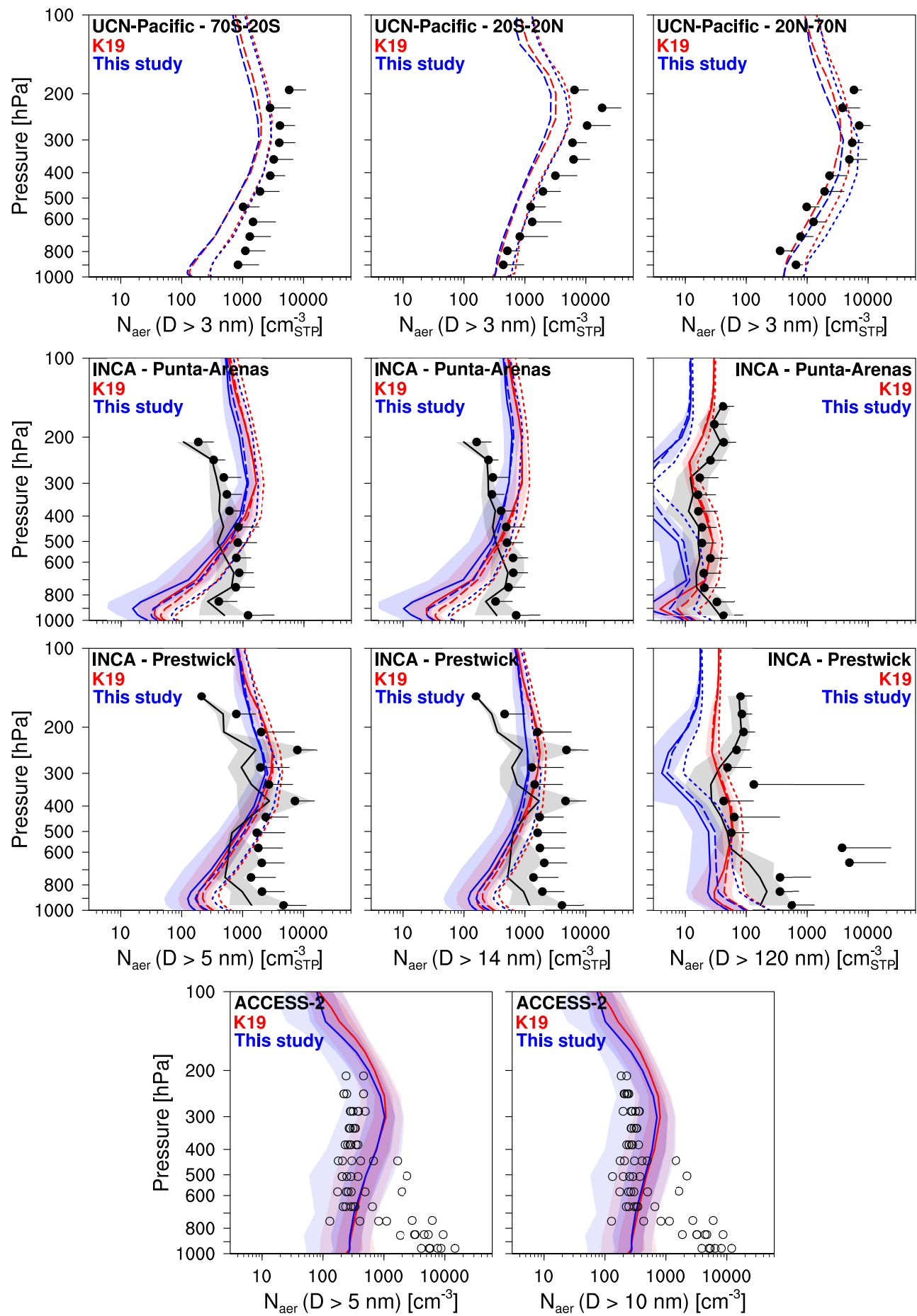

Figure S9. Same as Fig. S3, but for particle number concentrations with various cutoff diameters. 

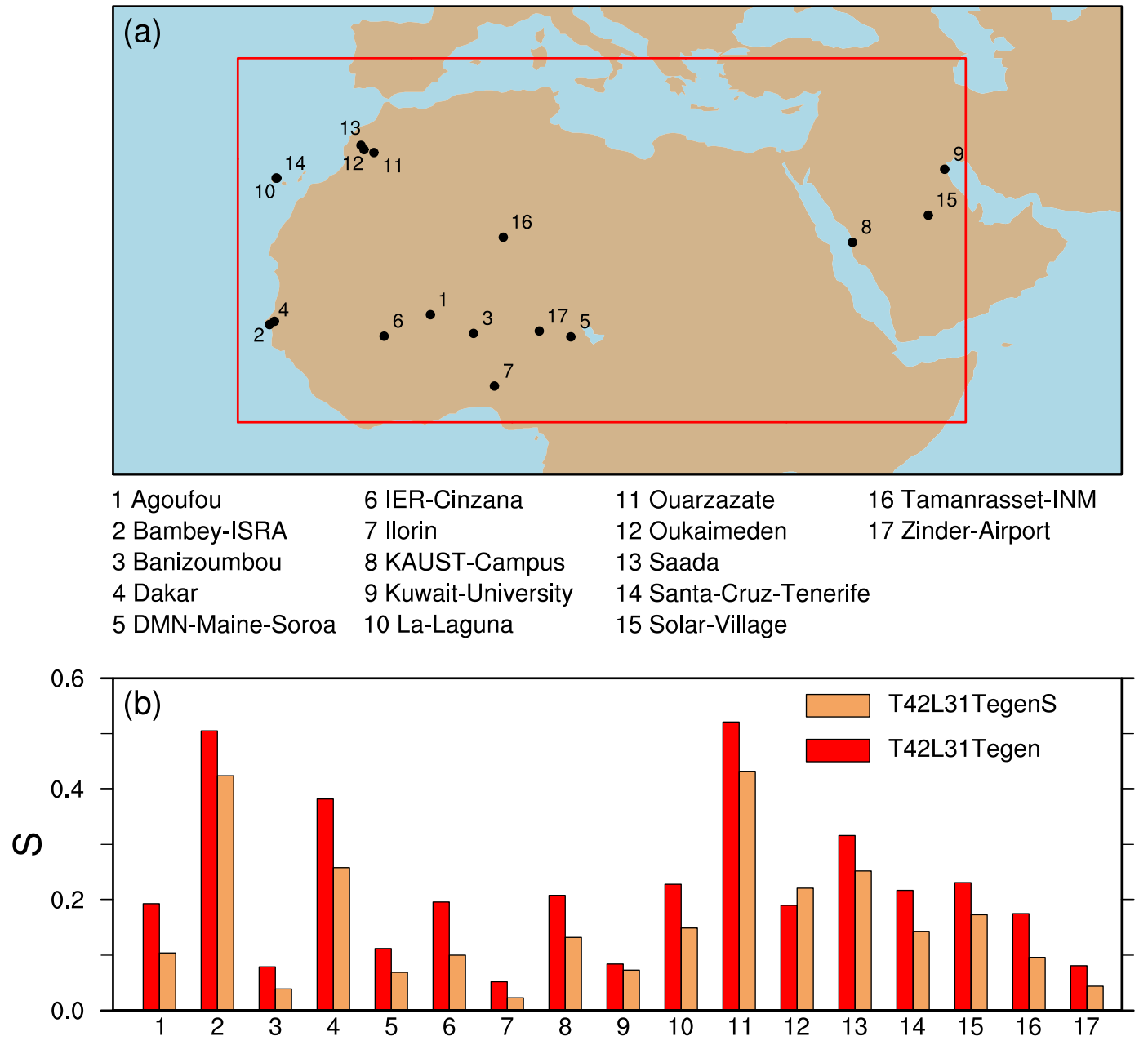

Figure S10. As in Fig. 4, but comparing AOD station data with the T42L31Tegen and T42L31TegenS model setups, i.e. varying the size distribution of emitted dust. See Sect. 3.3 in the paper for details. 